\title{
12
}

\section{An Evaluation of Modeling Green Infrastructure Using LID Controls}

\section{Matthew McCutcheon, Derek Wride and Josh Reinicke}

Green infrastructure is increasingly being considered for application in urban stormwater management designs. Many municipalities, regulatory agencies and advocacy groups promote the use of low impact development (LID) to reduce runoff and increase infiltration. To show LID benefits, engineers must quantify the advantages of green versus traditional grey infrastructure.

The United States Environmental Protection Agency (USEPA) updated its storm water management model (SWMM5) with explicit LID controls in 2009 to assist engineers in quantifying the benefits of green infrastructure. SWMM5 now simulates five LID devices: bio-retention cells, infiltration trenches, porous pavements, rain barrels and vegetated swales.

Limited documentation is available regarding modeling techniques using the LID controls, although the SWMM Applications Manual (Gironas et al., 2009) discusses modeling LID using SWMM5 features available before the LID controls were added. This study represents an initial evaluation of different SWMM5 modeling approaches using SWMM5 LID controls. No field measurements were performed. The discussion is limited to a modeling evaluation of the SWMM5 LID controls.

An example from the SWMM Applications Manual was chosen as the base case for this study. The specific example was chosen because it contains multiple sub catchments, each approximately five acres ( $2.03 \mathrm{ha})$ or less.

The example was modified from a developed condition without green infrastructure to include LID devices. Five subcatchments were altered to include LID controls. A sixth subcatchment was left as a control subcatchment. A seventh fully pervious subcatchment was also left as is. Several simulations were conducted to assess the effectiveness of the SWMM5 LID controls.

McCutcheon, M., D. Wride and J. Reinicke. 2012. "An Evaluation of Modeling Green Infrastructure Using LID Controls." Journal of Water Management Modeling R245-12. doi: 10.14796/JWMM.R245-12.

(C) CHI 2012 www.chijournal.org ISSN: 2292-6062 (Formerly in On Modeling Urban Water Systems. ISBN: 978-0-9808853-7-8) 
Each LID device was modeled as its own subcatchment and then as part of the existing subcatchment. Simulation results were inconsistent. In several simulations, the LID control increased peak and total runoff. Also, a simple sensitivity analysis indicated that only one parameter affected results. A third approach of simply routing impervious areas to pervious areas before sending runoff to an outlet was also modeled and produced results that showed a decrease in peak runoff values which indicate that the approach may sufficiently model the effect of green infrastructure.

\subsection{Methodology}

\subsubsection{Modeling Techniques}

Designed to capture surface runoff, LID practices provide detention, infiltration, evapotranspiration, or some combination of the three. SWMM5 represents LID practices through the LID Controls option in the Hydrology section of the Data tab. By defining the LID practices in this way, they are considered properties to be attributed to the individual subcatchments and multiple LID controls can be assigned to each subcatchment. SWMM5 allows the user to choose one of two approaches for placing LID controls:

1. Create a new subcatchment dedicated exclusively to a single LID control; and

2. Place one or more LID controls within an existing subcatchment, displacing an equal amount of non-LID area from the subcatchment.

Using the first approach, only one LID control is represented by a single subcatchment. In this configuration, the LID controls may only act in series. To make the LIDs work in series, simply route one LID subcatchment to another. Under this configuration, the LID controls cannot act in parallel because only one outlet can be specified for each subcatchment. If this approach is being used for an existing model (e.g. a retrofit situation or similar) after the new LID subcatchment is created, the original subcatchment's area, percent impervious, and width parameters must be adjusted to compensate for the area taken by the LID.

If this approach is used in a new model, the area of the LID subcatchment should not be double counted in the non-LID subcatchment area. Figure 12.1 shows the layout for using the first approach to modeling LIDs using the SWMM5 LID controls. 


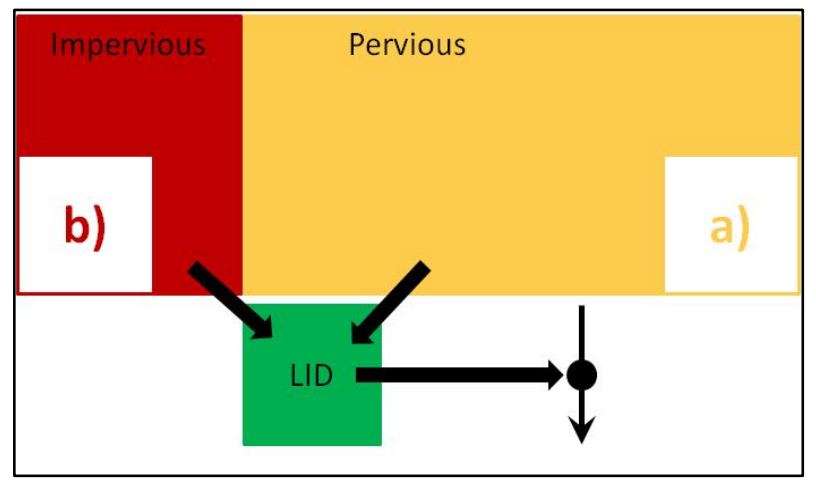

Figure 12.1 LID modeling approach 1 schematic.

Using the second approach, multiple LID controls can be placed in a single subcatchment. In this configuration, the LID controls can only act in parallel. It is not possible to route flow from one LID control to another when multiple LID controls are specified for a single subcatchment. When the LID controls act in parallel, each control accepts runoff from a different portion of the subcatchment. However, it is not possible to specify which portion of the runoff flows to a specific LID control, other than by specifying the type of tributary area (pervious or impervious). Under the second approach, the subcatchment's percent imperviousness and width parameters must be adjusted to reflect the inclusion of the LID control. Figure 12.2 shows the layout for using the second approach to modeling LIDs using the SWMM5 LID controls.

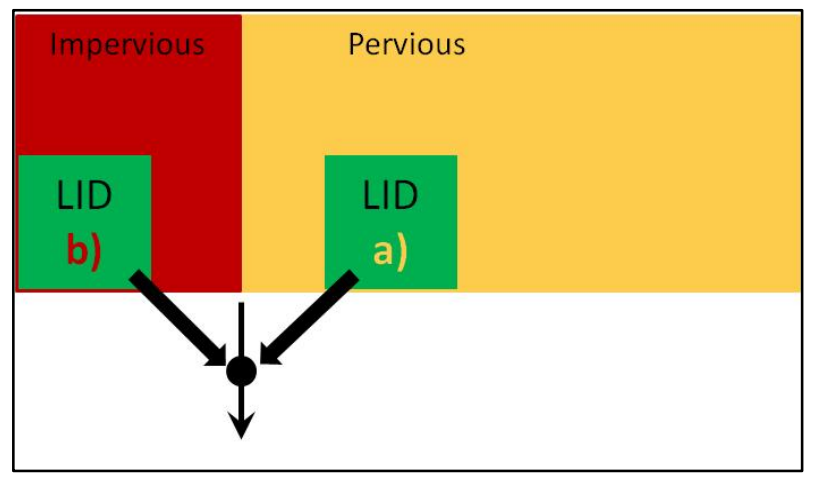

Figure 12.2 LID modeling approach 2 schematic.

The properties of the LID controls are specified on a per-unit-area basis allowing the same LID to be placed in several subcatchments with different areal 
coverage. Each LID control consists of a combination of vertical layers. A moisture balance between each layer is tracked during a SWMM5 simulation and is the basis for the LID results.

\subsubsection{SWMM5 Base Model}

The base model in this chapter was built from the example included in the downloadable SWMM5 Applications Manual. This example was chosen because it contains multiple subcatchments, each having a maximum area of 5 acres (2.03 ha). The example was modified from a developed condition without green infrastructure to include LID devices. Five subcatchments were altered to include LID controls (S1-S5). A sixth subcatchment was left as a control subcatchment (S6). A seventh fully pervious subcatchment was also left as is (S7). Figure 12.3 shows the layout of the base model. Several simulations were conducted to assess effectiveness of the SWMM5 LID controls.

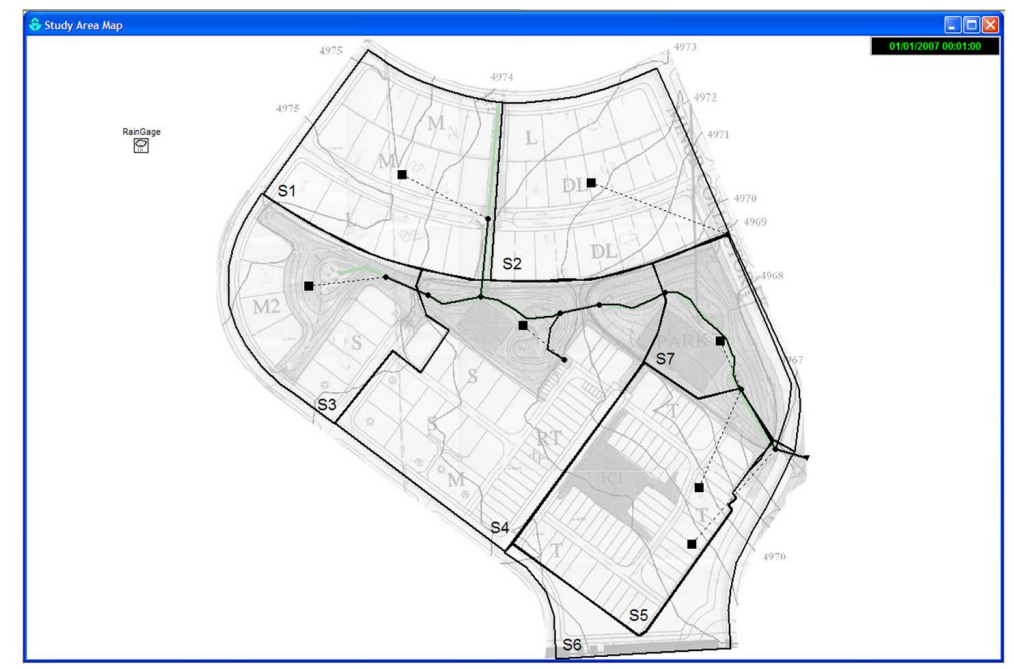

Figure 12.3 Model layout.

This study is limited to simulation results. No field data were collected. This evaluation method is not comprehensive and has limitations, but it is applicable for evaluating the results provided strictly by the LID control simulations.

\subsubsection{Simulation Procedure}

Each LID device was modeled as its own subcatchment and then as part of the existing subcatchment. The LID device was assigned $10 \%$ of the impervious or 
pervious catchment area, based on the type of control. For instance, Rain Barrels and Porous Pavement were assigned $10 \%$ of the impervious area while Bio-Retention, Infiltration Trenches, and Vegetative Swales were assigned 10\% of the previous area. Due to the highly localized nature of green infrastructure development, sizing guidelines are highly site dependent and no rule of thumb ratio of green infrastructure size to drainage area has been recognized (Heitz et al., 2000; Akan, 2002; Mungasavalli and Viraraghavan, 2006). An assumption of the ratio of LID to tributary area was required for this study. It was assumed that a typical residential lot could designate $10 \%$ of the total impervious or pervious area of the parcel for the implementation of green infrastructure.

Each LID control has its own unique set of input parameters. The parameters used in this study were obtained from the references provided at the end of this chapter. Based on the soil characteristics of the base model, the appropriate LID control parameters were selected from the published ranges. Simulations were conducted with and without LID controls present for a 3 month event and a 2 y event. Table 12.1 shows the characteristics of each storm event.

Table 12.1 Storm characteristics for 3 month and 2 y events used in simulations.

\begin{tabular}{ccc}
\hline Time $(\mathrm{h})$ & 3 month intensity (in./h) & 2 y intensity (in./h) \\
\hline $0: 00$ & 0.15 & 0.29 \\
$0: 05$ & 0.17 & 0.33 \\
$0: 10$ & 0.19 & 0.38 \\
$0: 15$ & 0.33 & 0.64 \\
$0: 20$ & 0.41 & 0.81 \\
$0: 25$ & 0.80 & 1.57 \\
$0: 30$ & 1.45 & 2.85 \\
$0: 35$ & 0.60 & 1.18 \\
$0: 40$ & 0.36 & 0.71 \\
$0: 45$ & 0.21 & 0.42 \\
$0: 50$ & 0.18 & 0.35 \\
$0: 55$ & 0.15 & 0.30 \\
$1: 00$ & 0.10 & 0.20 \\
$1: 05$ & 0.10 & 0.19 \\
$1: 10$ & 0.09 & 0.18 \\
$1: 15$ & 0.09 & 0.17 \\
$1: 20$ & 0.09 & 0.17 \\
$1: 25$ & 0.08 & 0.16 \\
$1: 30$ & 0.08 & 0.15 \\
$1: 35$ & 0.08 & 0.15 \\
$1: 40$ & 0.07 & 0.14 \\
$1: 45$ & 0.07 & 0.14 \\
$1: 50$ & 0.07 & 0.13 \\
$1: 55$ & 0.07 & 0.13 \\
\hline
\end{tabular}

The 2 y event is included with the base model from the SWMM Application Manual. The 2 y event was scaled to a 3 month event to preserve the shape of 
the rainfall hyetograph and to maintain the storm duration. Comparisons were made between the peak runoff and total runoff volume for each event with and without LID controls. It was expected that the LID devices would reduce both peak runoff and total runoff volume.

\subsection{Results and Discussion}

\subsubsection{Simulation Results Approach 1}

The results from all 3 month event separate LID subcatchment simulations are summarized in Tables 12.2 and 12.3.

Table 12.2 Peak runoff for 3 month event ( $\left.\mathrm{ft}^{3} / \mathrm{s}\right)$, approach 1 .

\begin{tabular}{llllllll}
\hline Model Scenario & S1 & S2 & S3 & S4 & S5 & S6 & S7 \\
\hline No LID & 3.67 & 4.22 & 2.15 & 4.89 & 5.76 & 2.56 \\
Bio-Retention & 3.49 & 4.03 & 2.03 & 4.63 & 5.61 & 2.56 & \\
Infiltration Trench & & & & & & 2.56 & \\
Porous Pavement & & & & & & 2.56 & \\
Rain Barrel & & & & & & 2.56 \\
Vegetative Swale & $\mathbf{3 . 8 6}$ & $\mathbf{4 . 3 4}$ & $\mathbf{2 . 4 6}$ & $\mathbf{5 . 2 9}$ & $\mathbf{5 . 7 9}$ & 2.56 \\
Impervious Routed to Pervious (No LID) & 2.30 & 2.94 & 0.97 & 2.71 & 5.45 & 2.56 \\
Impervious and Pervious Routed to Outlet (No LID) & $\mathbf{3 . 6 6}$ & $\mathbf{4 . 2 0}$ & $\mathbf{2 . 1 4}$ & $\mathbf{4 . 8 7}$ & $\mathbf{5 . 7 5}$ & 2.56 \\
Vegetative Swale - Unit Width 3 ft & $\mathbf{3 . 8 6}$ & $\mathbf{4 . 3 4}$ & $\mathbf{2 . 4 6}$ & $\mathbf{5 . 2 9}$ & $\mathbf{5 . 7 9}$ & 2.56 \\
Vegetative Swale - Unit Width 6 ft & $\mathbf{3 . 8 6}$ & $\mathbf{4 . 3 4}$ & $\mathbf{2 . 4 6}$ & $\mathbf{5 . 2 9}$ & $\mathbf{5 . 7 9}$ & 2.56 \\
Vegetative Swale - Unit Width 9 ft & $\mathbf{3 . 8 6}$ & $\mathbf{4 . 3 4}$ & $\mathbf{2 . 4 6}$ & $\mathbf{5 . 2 9}$ & $\mathbf{5 . 7 9}$ & 2.56 \\
Impervious Area & 3.70 & 4.27 & 0.90 & 4.90 & 6.01 & 2.69 \\
Pervious Area & & & & & & & \\
LID Area & & & & & & & \\
\hline
\end{tabular}

Table 12.3 Total runoff volume for 3 month event (MG), approach 1.

\begin{tabular}{llllllll}
\hline Model Scenario & S1 & S2 & S3 & S4 & S5 & S6 & S7 \\
\hline No LID & 0.03 & 0.04 & 0.02 & 0.04 & 0.05 & 0.02 & \\
Bio-Retention & 0.02 & 0.03 & 0.01 & 0.02 & 0.05 & 0.02 & \\
Infiltration Trench & & & & & & 0.02 & \\
Porous Pavement & & & & & & 0.02 & \\
Rain Barrel & & & & & & 0.02 & \\
Vegetative Swale & 0.03 & 0.04 & 0.02 & $\mathbf{0 . 0 5}$ & 0.05 & 0.02 & \\
Impervious Routed to Pervious (No LID) & 0.02 & 0.03 & 0.01 & 0.03 & 0.05 & 0.02 & \\
Impervious and Pervious Routed to Outlet (No LID) & 0.03 & 0.04 & 0.02 & 0.04 & 0.05 & 0.02 \\
Vegetative Swale - Unit Width 3 ft & 0.03 & 0.04 & 0.02 & $\mathbf{0 . 0 5}$ & 0.05 & 0.02 \\
Vegetative Swale - Unit Width 6 ft & 0.03 & 0.04 & 0.02 & $\mathbf{0 . 0 5}$ & 0.05 & 0.02 \\
Vegetative Swale - Unit Width 9 ft & 0.03 & 0.04 & 0.02 & $\mathbf{0 . 0 5}$ & 0.05 & 0.02 \\
Impervious Area & 0.03 & 0.04 & 0.01 & 0.04 & 0.05 & 0.02 \\
Pervious Area & & & & & & 0.02 \\
LID Area & & & & & & 0.02 & \\
\hline
\end{tabular}


Inconsistencies in the results are evident (bold font values in tables). The peak runoff values indicated by the model for the vegetative swale are greater than the peak runoff without LID present. The most consistent, reliable and reasonable results for both peak runoff flow rate and total runoff volume were generated from routing impervious areas to pervious areas prior to routing the surface flow to a receiving junction node. For the simulations where impervious runoff was routed to a pervious catchment, no LID control was modeled.

Because no runoff was generated for the infiltration trench, porous pavement, and rain barrel LIDs, it is assumed that these devices are grossly oversized. No conclusions can be drawn from the results of the simulations that do not produce runoff. The total runoff volume modeled for the vegetative swale is greater in subcatchment S4 than the total runoff volume from the model without LID controls present.

The results from all $2 \mathrm{y}$ event separate LID subcatchment simulations are summarized in Tables 12.4 and 12.5. Inconsistencies in the results are evident (bold font values in tables). The peak runoff values indicated by the model for the vegetative swale are greater than the peak runoff without LID present. For several subcatchments with bioretention (S1, S3, and S4) the modeled peak runoff is greater than the modeled peak runoff without LID present. The most consistent, reliable and reasonable results for both peak runoff flow rate and total runoff volume were generated from routing impervious areas to pervious areas prior to routing the surface flow to a receiving junction node. For the simulations where impervious runoff was routed to a pervious catchment, no LID control was modeled. Because no runoff was generated for the infiltration trench, porous pavement and rain barrel LIDs, it is assumed that these devices are grossly oversized. No conclusions can be drawn from the results of the simulations that do not produce runoff. No inconsistencies were noted when the results for the total runoff volume for the $2 \mathrm{y}$ event were modeled.

Table 12.4 Peak runoff for 2 y event ( $\left.\mathrm{ft}^{3} / \mathrm{s}\right)$, approach 1.

\begin{tabular}{llllllll}
\hline Model Scenario & S1 & S2 & S3 & S4 & S5 & S6 & S7 \\
\hline No LID & 7.35 & 8.47 & 4.24 & 9.70 & 11.75 & 5.23 & \\
Bio-Retention & $\mathbf{7 . 4 0}$ & 8.47 & $\mathbf{4 . 5 0}$ & $\mathbf{9 . 9 7}$ & 11.61 & 5.23 & \\
Infiltration Trench & & & & & & 5.23 & \\
Porous Pavement & & & & & & 5.23 & \\
Rain Barrel & & & & & & 5.23 & \\
Vegetative Swale & $\mathbf{7 . 8 1}$ & $\mathbf{8 . 8 3}$ & $\mathbf{4 . 8 8}$ & $\mathbf{1 0 . 5 9}$ & $\mathbf{1 1 . 8 1}$ & 5.23 & \\
Impervious Routed to Pervious (No LID) & 6.40 & 7.59 & 3.58 & 8.24 & 11.55 & 5.23 & \\
Impervious and Pervious Routed to Outlet (No LID) & 7.34 & 8.45 & 4.23 & 9.68 & 11.74 & 5.23 & \\
Vegetative Swale - Unit Width 3 ft & $\mathbf{7 . 8 1}$ & $\mathbf{8 . 8 3}$ & $\mathbf{4 . 8 8}$ & $\mathbf{1 0 . 5 9}$ & $\mathbf{1 1 . 8 1}$ & 5.23 & \\
Vegetative Swale - Unit Width 6 ft & $\mathbf{7 . 8 1}$ & $\mathbf{8 . 8 3}$ & $\mathbf{4 . 8 8}$ & $\mathbf{1 0 . 5 9}$ & $\mathbf{1 1 . 8 1}$ & 5.23 \\
Vegetative Swale - Unit Width 9 ft & $\mathbf{7 . 8 1}$ & $\mathbf{8 . 8 3}$ & $\mathbf{4 . 8 8}$ & $\mathbf{1 0 . 5 9}$ & $\mathbf{1 1 . 8 1}$ & 5.23 \\
Impervious Area & 7.37 & 8.51 & 1.77 & 9.71 & 11.98 & 5.36 & \\
Pervious Area & & & & & & & \\
LID Area & & & & & & & \\
\hline
\end{tabular}


Table 12.5 Total runoff volume for 2 y event (MG), approach 1.

\begin{tabular}{llllllll}
\hline Model Scenario & S1 & S2 & S3 & S4 & S5 & S6 & S7 \\
\hline No LID & 0.07 & 0.08 & 0.04 & 0.09 & 0.11 & 0.05 & \\
Bio-Retention & 0.06 & 0.07 & 0.03 & 0.07 & 0.10 & 0.05 & \\
Infiltration Trench & & & & & & 0.05 & \\
Porous Pavement & & & & & & 0.05 & \\
Rain Barrel & & & & & & 0.05 & \\
Vegetative Swale & 0.07 & 0.08 & 0.04 & 0.09 & 0.11 & 0.05 & \\
Impervious Routed to Pervious (No LID) & 0.06 & 0.07 & 0.03 & 0.08 & 0.10 & 0.05 & \\
Impervious and Pervious Routed to Outlet (No LID) & & & & & & 0.05 & \\
Vegetative Swale - Unit Width 3 ft & 0.07 & 0.08 & 0.04 & 0.09 & 0.11 & 0.05 \\
Vegetative Swale - Unit Width 6 ft & 0.07 & 0.08 & 0.04 & 0.09 & 0.11 & 0.05 \\
Vegetative Swale - Unit Width 9 ft & 0.07 & 0.08 & 0.04 & 0.09 & 0.11 & 0.05 \\
Impervious Area & 0.07 & 0.08 & 0.02 & 0.09 & 0.11 & 0.05 \\
Pervious Area & & & & & & 0.05 & \\
LID Area & & & & & & 0.05 & \\
\hline
\end{tabular}

\subsubsection{Simulation Results Approach 2}

The results from all 3 month event simulations where the LID area was included in the original subcatchment are summarized in Tables 12.6 and 12.7.

Table 12.6 Peak runoff for 3 month event ( $\left.\mathrm{ft}^{3} / \mathrm{s}\right)$, approach 2.

\begin{tabular}{llllllll}
\hline Model Scenario & S1 & S2 & S3 & S4 & S5 & S6 & S7 \\
\hline No LID & 3.67 & 4.22 & 2.15 & 4.89 & 5.76 & 2.56 & \\
Bio-Retention & 3.44 & 3.99 & 1.96 & 4.55 & 5.58 & 2.56 & \\
Infiltration Trench & & & & & & 2.56 & \\
Porous Pavement & & & & & & 2.56 & \\
Rain Barrel & & & & & & 2.56 & \\
Vegetative Swale & $\mathbf{3 . 8 1}$ & $\mathbf{4 . 3 3}$ & $\mathbf{2 . 3 5}$ & $\mathbf{5 . 1 5}$ & $\mathbf{5 . 7 8}$ & 2.56 & \\
Vegetative Swale - Unit Width 3 ft & $\mathbf{3 . 8 1}$ & $\mathbf{4 . 3 3}$ & $\mathbf{2 . 3 5}$ & $\mathbf{5 . 1 5}$ & $\mathbf{5 . 7 8}$ & 2.56 & \\
Vegetative Swale - Unit Width 6 ft & $\mathbf{3 . 8 1}$ & $\mathbf{4 . 3 3}$ & $\mathbf{2 . 3 5}$ & $\mathbf{5 . 1 5}$ & $\mathbf{5 . 7 8}$ & 2.56 & \\
Vegetative Swale - Unit Width 9 ft & $\mathbf{3 . 8 1}$ & $\mathbf{4 . 3 3}$ & $\mathbf{2 . 3 5}$ & $\mathbf{5 . 1 5}$ & $\mathbf{5 . 7 8}$ & 2.56 & \\
\hline
\end{tabular}

Table 12.7 Total runoff volume for 3 month event (MG), approach 2.

\begin{tabular}{llllllll}
\hline Model Scenario & S1 & S2 & S3 & S4 & S5 & S6 & S7 \\
\hline No LID & 0.03 & 0.04 & 0.02 & 0.04 & 0.05 & 0.02 \\
Bio-Retention & 0.02 & 0.03 & 0.01 & 0.02 & 0.05 & 0.02 \\
Infiltration Trench & & & & & & 0.02 \\
Porous Pavement & & & & & & 0.02 \\
Rain Barrel & & & & & & 0.02 \\
Vegetative Swale & 0.03 & 0.04 & 0.02 & 0.04 & 0.05 & 0.02 \\
Vegetative Swale - Unit Width 3 ft & 0.03 & 0.04 & 0.02 & 0.04 & 0.05 & 0.02 \\
Vegetative Swale - Unit Width 6 ft & 0.03 & 0.04 & 0.02 & 0.04 & 0.05 & 0.02 \\
Vegetative Swale - Unit Width 9ft & 0.03 & 0.04 & 0.02 & 0.04 & 0.05 & 0.02 \\
\hline
\end{tabular}


Inconsistencies in the results are evident (bold font values in tables). The peak runoff values indicated by the model for the Vegetative Swale are greater than the peak runoff without LID present. Because no runoff was generated for the infiltration trench, porous pavement, and rain barrel LIDs, it is assumed that these devices are grossly oversized. No conclusions can be drawn from the results of the simulations that do not produce runoff. In Table 12.7, no inconsistencies were noted when the results for the total runoff volume for the 3 month event were modeled.

The results from all 2 y event separate LID subcatchment simulations are summarized in Tables 12.8 and 12.9. Inconsistencies in the results are evident (bold font values in tables). The peak runoff values indicated by the model for the vegetative swale are greater than the peak runoff without LID present. For one subcatchment with bioretention (S3) the modeled peak runoff is greater than the modeled peak runoff without LID present. Because no runoff was generated for the infiltration trench, porous pavement, and rain barrel LIDs, it is assumed that these devices are grossly oversized. No conclusions can be drawn from the results of the simulations that do not produce runoff. In Table 12.9, no inconsistencies were noted when the results for the total runoff volume for the 2 y event were modeled.

Table 12.8 Peak runoff for 2 y event $\left(\mathrm{ft}^{3} / \mathrm{s}\right)$, approach 2 .

\begin{tabular}{llllllll}
\hline Model Scenario & S1 & S2 & S3 & S4 & S5 & S6 & S7 \\
\hline No LID & 7.35 & 8.47 & 4.24 & 9.70 & 11.75 & 5.23 & \\
Bio-Retention & 7.26 & 8.34 & $\mathbf{4 . 2 9}$ & 9.65 & 11.54 & 5.23 & \\
Infiltration Trench & & & & & & 5.23 & \\
Porous Pavement & & & & & & 5.23 & \\
Rain Barrel & & & & & & 5.23 & \\
Vegetative Swale & $\mathbf{7 . 6 1}$ & $\mathbf{8 . 6 7}$ & $\mathbf{4 . 6 3}$ & $\mathbf{1 0 . 1 9}$ & $\mathbf{1 1 . 7 8}$ & 5.23 & \\
Vegetative Swale - Unit Width 3 ft & $\mathbf{7 . 6 1}$ & $\mathbf{8 . 6 7}$ & $\mathbf{4 . 6 3}$ & $\mathbf{1 0 . 1 9}$ & $\mathbf{1 1 . 7 8}$ & 5.23 & \\
Vegetative Swale - Unit Width 6 ft & $\mathbf{7 . 6 1}$ & $\mathbf{8 . 6 7}$ & $\mathbf{4 . 6 3}$ & $\mathbf{1 0 . 1 9}$ & $\mathbf{1 1 . 7 8}$ & 5.23 & \\
Vegetative Swale - Unit Width 9 ft & $\mathbf{7 . 6 1}$ & $\mathbf{8 . 6 7}$ & $\mathbf{4 . 6 3}$ & $\mathbf{1 0 . 1 9}$ & $\mathbf{1 1 . 7 8}$ & 5.23 & \\
\hline
\end{tabular}

Table 12.9 Total runoff volume for 2 y event (MG), approach 2.

\begin{tabular}{llllllll}
\hline Model Scenario & S1 & S2 & S3 & S4 & S5 & S6 & S7 \\
\hline No LID & 0.07 & 0.08 & 0.04 & 0.09 & 0.11 & 0.05 & \\
Bio-Retention & 0.05 & 0.06 & 0.03 & 0.09 & 0.10 & 0.05 & \\
Infiltration Trench & & & & & & 0.05 & \\
Porous Pavement & & & & & & 0.05 & \\
Rain Barrel & & & & & & 0.05 & \\
Vegetative Swale & 0.07 & 0.08 & 0.04 & 0.09 & 0.11 & 0.05 & \\
Vegetative Swale - Unit Width 3ft & 0.07 & 0.08 & 0.04 & 0.09 & 0.11 & 0.05 & \\
Vegetative Swale - Unit Width 6 ft & 0.07 & 0.08 & 0.04 & 0.09 & 0.11 & 0.05 & \\
Vegetative Swale - Unit Width 9ft & 0.07 & 0.08 & 0.04 & 0.09 & 0.11 & 0.05 & \\
\hline
\end{tabular}




\subsubsection{Simulation Results Sensitivity Analysis}

A sensitivity analysis was performed on the vegetative swale LID control as its own subcatchment (Table 12.10) and as part of the existing subcatchment (Table 12.11) for the 2 y event.

Table 12.10 Peak runoff sensitivity analysis $\left(\mathrm{ft}^{3} / \mathrm{s}\right)$, approach 1 .

\begin{tabular}{llllllll}
\hline Model Scenario & S1 & S2 & S 3 & S4 & S5 & S6 & S7 \\
\hline No LID & 7.35 & 8.47 & 4.24 & 9.70 & 11.75 & 5.23 & \\
Storage Depth 2 inches & $\mathbf{7 . 8 1}$ & $\mathbf{8 . 8 3}$ & $\mathbf{4 . 8 8}$ & $\mathbf{1 0 . 5 9}$ & $\mathbf{1 1 . 8 1}$ & 5.23 & \\
Storage Depth 20 inches & $\mathbf{7 . 8 1}$ & $\mathbf{8 . 8 3}$ & $\mathbf{4 . 8 8}$ & $\mathbf{1 0 . 5 9}$ & $\mathbf{1 1 . 8 1}$ & 5.23 & \\
Storage Depth 200 inches & $\mathbf{7 . 8 1}$ & $\mathbf{8 . 8 3}$ & $\mathbf{4 . 8 8}$ & $\mathbf{1 0 . 5 9}$ & $\mathbf{1 1 . 8 1}$ & 5.23 & \\
Vegetative Cover 1\% & 0.11 & 0.14 & 0.05 & 0.08 & $\mathbf{1 6 . 0 8}$ & 5.23 & \\
Vegetative Cover 10\% & 0.10 & 0.13 & 0.04 & 0.07 & $\mathbf{1 2 . 9 0}$ & 5.23 & \\
Vegetative Cover 50\% & 1.83 & 5.90 & 0.02 & 0.46 & $\mathbf{1 1 . 7 8}$ & 5.23 & \\
Vegetative Cover 75\% & $\mathbf{1 1 . 5 4}$ & $\mathbf{9 . 3 8}$ & 1.84 & $\mathbf{1 1 . 2 6}$ & $\mathbf{1 1 . 7 9}$ & 5.23 & \\
Vegetative Cover 99\% & $\mathbf{7 . 8 1}$ & $\mathbf{8 . 8 3}$ & $\mathbf{4 . 8 8}$ & $\mathbf{1 0 . 5 9}$ & $\mathbf{1 1 . 8 1}$ & 5.23 & \\
Vegetative Cover 100\% & $\mathbf{7 . 8 1}$ & $\mathbf{8 . 8 3}$ & $\mathbf{4 . 8 8}$ & $\mathbf{1 0 . 5 9}$ & $\mathbf{1 1 . 8 1}$ & 5.23 & \\
Manning's N 0.01 & $\mathbf{7 . 8 1}$ & $\mathbf{8 . 8 3}$ & $\mathbf{4 . 8 8}$ & $\mathbf{1 0 . 5 9}$ & $\mathbf{1 1 . 8 1}$ & 5.23 & \\
Manning's N 0.15 & $\mathbf{7 . 8 1}$ & $\mathbf{8 . 8 3}$ & $\mathbf{4 . 8 8}$ & $\mathbf{1 0 . 5 9}$ & $\mathbf{1 1 . 8 1}$ & 5.23 & \\
Manning's N 0.40 & $\mathbf{7 . 8 1}$ & $\mathbf{8 . 8 3}$ & $\mathbf{4 . 8 8}$ & $\mathbf{1 0 . 5 9}$ & $\mathbf{1 1 . 8 1}$ & 5.23 & \\
Surface Slope 0.1\% & $\mathbf{7 . 8 1}$ & $\mathbf{8 . 8 3}$ & $\mathbf{4 . 8 8}$ & $\mathbf{1 0 . 5 9}$ & $\mathbf{1 1 . 8 1}$ & 5.23 & \\
Surface Slope 1\% & $\mathbf{7 . 8 1}$ & $\mathbf{8 . 8 3}$ & $\mathbf{4 . 8 8}$ & $\mathbf{1 0 . 5 9}$ & $\mathbf{1 1 . 8 1}$ & 5.23 & \\
Surface Slope 10\% & $\mathbf{7 . 8 1}$ & $\mathbf{8 . 8 3}$ & $\mathbf{4 . 8 8}$ & $\mathbf{1 0 . 5 9}$ & $\mathbf{1 1 . 8 1}$ & 5.23 & \\
Side Slope 1\% & $\mathbf{7 . 8 1}$ & $\mathbf{8 . 8 3}$ & $\mathbf{4 . 8 8}$ & $\mathbf{1 0 . 5 9}$ & $\mathbf{1 1 . 8 1}$ & 5.23 & \\
Side Slope 5\% & $\mathbf{7 . 8 1}$ & $\mathbf{8 . 8 3}$ & $\mathbf{4 . 8 8}$ & $\mathbf{1 0 . 5 9}$ & $\mathbf{1 1 . 8 1}$ & 5.23 & \\
Side Slope 10\% & $\mathbf{7 . 8 1}$ & $\mathbf{8 . 8 3}$ & $\mathbf{4 . 8 8}$ & $\mathbf{1 0 . 5 9}$ & $\mathbf{1 1 . 8 1}$ & 5.23 & \\
\hline
\end{tabular}

Table 12.11 Peak runoff sensitivity analysis $\left(\mathrm{ft}^{3} / \mathrm{s}\right)$, approach 2 .

\begin{tabular}{llllllll}
\hline Model Scenario & S1 & S2 & S3 & S4 & S5 & S6 & S7 \\
\hline No LID & 7.35 & 8.47 & 4.24 & 9.70 & 11.75 & 5.23 & \\
Storage Depth 2 inches & $\mathbf{7 . 6 1}$ & $\mathbf{8 . 6 7}$ & $\mathbf{4 . 6 3}$ & $\mathbf{1 0 . 1 9}$ & $\mathbf{1 1 . 7 8}$ & 5.23 & \\
Storage Depth 20 inches & $\mathbf{7 . 6 1}$ & $\mathbf{8 . 6 7}$ & $\mathbf{4 . 6 3}$ & $\mathbf{1 0 . 1 9}$ & $\mathbf{1 1 . 7 8}$ & 5.23 & \\
Storage Depth 200 inches & $\mathbf{7 . 6 1}$ & $\mathbf{8 . 6 7}$ & $\mathbf{4 . 6 3}$ & $\mathbf{1 0 . 1 9}$ & $\mathbf{1 1 . 7 8}$ & 5.23 & \\
Vegetative Cover 1\% & 0.12 & 0.15 & 0.05 & 0.09 & $\mathbf{1 5 . 9 8}$ & 5.23 & \\
Vegetative Cover 10\% & 0.11 & 0.14 & 0.05 & 0.08 & $\mathbf{1 4 . 4 0}$ & 5.23 & \\
Vegetative Cover 50\% & 1.90 & 6.09 & 0.03 & 0.59 & $\mathbf{1 1 . 7 7}$ & 5.23 & \\
Vegetative Cover 75\% & $\mathbf{1 1 . 1 3}$ & $\mathbf{1 0 . 2 4}$ & 1.55 & $\mathbf{1 1 . 3 8}$ & $\mathbf{1 1 . 7 8}$ & 5.23 & \\
Vegetative Cover 99\% & $\mathbf{7 . 6 0}$ & $\mathbf{8 . 6 7}$ & $\mathbf{4 . 6 3}$ & $\mathbf{1 0 . 1 9}$ & $\mathbf{1 1 . 7 8}$ & 5.23 & \\
Vegetative Cover 100\% & $\mathbf{7 . 6 1}$ & $\mathbf{8 . 6 7}$ & $\mathbf{4 . 6 3}$ & $\mathbf{1 0 . 1 9}$ & $\mathbf{1 1 . 7 8}$ & 5.23 & \\
Manning's N 0.01 & $\mathbf{7 . 6 1}$ & $\mathbf{8 . 6 7}$ & $\mathbf{4 . 6 3}$ & $\mathbf{1 0 . 1 9}$ & $\mathbf{1 1 . 7 8}$ & 5.23 & \\
Manning's N 0.15 & $\mathbf{7 . 6 1}$ & $\mathbf{8 . 6 7}$ & $\mathbf{4 . 6 3}$ & $\mathbf{1 0 . 1 9}$ & $\mathbf{1 1 . 7 8}$ & 5.23 & \\
Manning's N 0.40 & $\mathbf{7 . 6 1}$ & $\mathbf{8 . 6 7}$ & $\mathbf{4 . 6 3}$ & $\mathbf{1 0 . 1 9}$ & $\mathbf{1 1 . 7 8}$ & 5.23 & \\
Surface Slope 0.1\% & $\mathbf{7 . 6 1}$ & $\mathbf{8 . 6 7}$ & $\mathbf{4 . 6 3}$ & $\mathbf{1 0 . 1 9}$ & $\mathbf{1 1 . 7 8}$ & 5.23 & \\
Surface Slope 1\% & $\mathbf{7 . 6 1}$ & $\mathbf{8 . 6 7}$ & $\mathbf{4 . 6 3}$ & $\mathbf{1 0 . 1 9}$ & $\mathbf{1 1 . 7 8}$ & 5.23 & \\
Surface Slope 10\% & $\mathbf{7 . 6 1}$ & $\mathbf{8 . 6 7}$ & $\mathbf{4 . 6 3}$ & $\mathbf{1 0 . 1 9}$ & $\mathbf{1 1 . 7 8}$ & 5.23 & \\
Side Slope 1\% & $\mathbf{7 . 6 1}$ & $\mathbf{8 . 6 7}$ & $\mathbf{4 . 6 3}$ & $\mathbf{1 0 . 1 9}$ & $\mathbf{1 1 . 7 8}$ & 5.23 & \\
Side Slope 5\% & $\mathbf{7 . 6 1}$ & $\mathbf{8 . 6 7}$ & $\mathbf{4 . 6 3}$ & $\mathbf{1 0 . 1 9}$ & $\mathbf{1 1 . 7 8}$ & 5.23 & \\
Side Slope 10\% & $\mathbf{7 . 6 1}$ & $\mathbf{8 . 6 7}$ & $\mathbf{4 . 6 3}$ & $\mathbf{1 0 . 1 9}$ & $\mathbf{1 1 . 7 8}$ & 5.23 & \\
\hline
\end{tabular}


Each parameter was isolated and varied by several orders of magnitude to test the robustness of the model. For almost every sensitivity simulation, the peak runoff increased (bold font values in tables). This is the opposite of the expected performance of the LID. Results of the sensitivity analysis indicate that only the amount of vegetative cover influences the model results. This parameter is input as the percentage of the surface area covered by vegetation. The greatest reductions in runoff are seen for the lower percentages of vegetative cover. This result was not expected and leads to some uncertainty in the reliability of its application.

\subsection{Findings and Observations}

With the increasing interest in understanding how green infrastructure may be utilized to meet numerous wet weather flow demands, the LID controls are a welcome addition to SWMM5. Many public and private entities are considering the use of green infrastructure in future development or as remediation techniques for stormwater problems. The SWMM LID controls are potentially a useful tool for analyzing the impacts of green infrastructure. The proper implementation and representation of green infrastructure in the SWMM5 model is critical to generating reliable results.

The model simulation results presented in this chapter indicate inconsistencies regarding the expectation of the results. It was expected that the implementation of LID controls would reduce the peak runoff flow rates from the catchments and reduce the total runoff volume, or at least stay about the same based on the model setup, but certainly not that they would increase. Runoff results from the 3 month bioretention simulations as well as all vegetative swale simulations show an increase in the peak runoff flow rate. This is not only counter-intuitive and unexpected, it is clearly incorrect. The LID control type modeled on a specific catchment also contributed to the variability in magnitude and direction of peak runoff flow rates. Total runoff volume appeared to produce more consistent results than peak runoff, meaning that total runoff volume decreased or remained constant depending on precipitation depth. The most consistent, reliable, and reasonable results for both peak runoff flow rate and total runoff volume were generated from routing impervious areas to pervious areas prior to routing the surface flow to a receiving junction node.

The sensitivity analysis shows that changing parameters of the vegetative swale LID control by orders of magnitude had little or no impact on the results. The Vegetative Cover parameter did impact the results of the sensitivity analysis and produced questionable outcomes.

This evaluation raised some questions and concerns regarding the SWMM5 LID controls. We recognize that it is not a comprehensive evaluation of the 
topic. Some potential additional steps to better understand the LID controls would be to collect field data to calibrate the model using different LID practices. Further evaluation could also be helpful by utilizing a continuous rainfall record that includes a range of rainfall events to better understand how the LID controls function. Based on the current model simulation results from this initial evaluation, it is recommended to use the SWMM5 LID controls with caution.

\section{References}

Akan, A. O. Modified Rational Method for Sizing Infiltration Structures. Canadian Journal of Civil Engineering, Vol. 29, No. 4, August 2002.

Gironas, J., Roesner, L. A. and Davis, J. Storm Water Management Model Applications Manual. USEPA EPA/600/R-09/077, July 2009.

Heitz, L. F., S. Khosrowpanah, and J. Nelson. Sizing of Surface Water Runoff Detention Ponds for Water Quality Improvement. Journal of the American Water Resources Association, Vol. 36, Issue 3, June 2000.

Mungasavalli, D. P. and T. Viraraghavan. Constructed Wetlands for Stormwater Management: A Review. Fresenius Environmental Bulletin, Vol. 15, No. 11, November 2006 .

\section{Background Sources}

ACCWP (Alameda Countywide Clean Water Program). Stormwater Technical Guidance. September 20, 2006.

Davis, Allen P. Field Performance of Bioretention: Hydrology Impacts. Journal of Hydrologic Engineering, Vol. 13, No. 2, February 1, 2008.

http://msw.cecs.ucf.edu/AndFiles/hlp2.html

http://www.bfenvironmental.com/pdfs/veggieSwale.pdf

http://www.brisbane.qld.gov.au/documents/building_development/subdivision_developm ent/wsud_chapt3_bioretention_swales.pdf

http://www.cabmphandbooks.com/Documents/Development/TC-30.pdf

http://www.co.pg.md.us/Government/AgencyIndex/DER/ESG/Bioretention/pdf/bioretent ion_design_manual.pdf

http://www.greenroads.us/files/140.pdf

http://www.sws-sssd.org_images/RainGarden.jpg

KCT (Knox County Tennessee). Storm Water Management Manual. April 22, 2008.

McCutcheon, Matthew D. Modeling Exfiltrating Storm Sewers Using SWMM. MS

Thesis. University of Cincinnati, Cincinnati, 2010. Print.

PGCMD (Prince George's County, Maryland). Bioretention Design Specifications and Criteria. November 13, 2002.

Rossman, Lewis A. Storm Water Management Model User's Manual Version 5.0. EPA600-R-05-040. July, 2010.

Smullen, James T., R. Dwayne Myers and Shannon K. Reynolds. A Green Approach to Combined Sewer Overflow Control: Source Control Implementation on a Watershed Scale. May 14, 2008. 
TWRRC (Tennessee Water Resources Research Center). Guide to the Selection \& Design of Stormwater Best Management Practices (BMPs). March, 2003.

USEPA. BMP Modeling Concepts and Simulation. EPA-600-R-06-033. July, 2006.

USEPA. National Management Measures to Control Nonpoint Source Pollution from Urban Areas. EPA-841-B-05-004. November, 2005.

USEPA. Storm Water Technology Fact Sheet Infiltration Trench. EPA-832-F-99-019. September, 1999a.

USEPA. Storm Water Technology Fact Sheet Vegetated Swale. EPA-832-F-99-006.

September, 1999b.

USEPA. What is a Rain Barrel? August, 2009. 
